Article

\title{
Combining Phenological Camera Photos and MODIS Reflectance Data to Predict GPP Daily Dynamics for Alpine Meadows on the Tibetan Plateau
}

\author{
Xuqiang Zhou ${ }^{1,2}$, Xufeng Wang ${ }^{2, *(1)}$, Songlin Zhang ${ }^{1}$, Yang Zhang ${ }^{2}$ and Xuejie Bai ${ }^{2}$ \\ 1 College of Geography and Environment Sciences, Northwest Normal University, Lanzhou 730070, China; \\ 2018222384@nwnu.edu.cn (X.Z.); zhangsonglin65@nwnu.edu.cn (S.Z.) \\ 2 Key Laboratory of Remote Sensing of Gansu Province, Heihe Remote Sensing Experimental Research \\ Station, Northwest Institute of Eco-Environment and Resources, Chinese Academy of Sciences, \\ Lanzhou 730000, China; zhangyang@1zb.ac.cn (Y.Z.); baixj@lzb.ac.cn (X.B.) \\ * Correspondence: wangxufeng@1zb.ac.cn; Tel.: +86-931-4967724
}

Received: 19 October 2020; Accepted: 11 November 2020; Published: 13 November 2020

\begin{abstract}
Gross primary production (GPP) is the overall photosynthetic fixation of carbon per unit space and time. Due to uncertainties resulting from clouds, snow, aerosol, and topography, it is a challenging task to accurately estimate daily GPP. Daily digital photos from a phenological camera record vegetation daily greenness dynamics with little cloud or aerosol disturbance. It can be fused with satellite remote sensing data to improve daily GPP prediction accuracy. In this study, we combine the two types of datasets to improve the estimation accuracy of GPP for alpine meadow on the Tibetan Plateau. To examine the performance of different methods and vegetation indices (VIs), three experiments were designed. First, GPP was estimated with the light use efficiency (LUE) model with the green chromatic coordinate (GCC) from the phenological camera and vegetation index from MODIS, respectively. Second, GPP was estimated with the Backpropagation neural network machine learning algorithm (BNNA) method with GCC from the phenological camera and vegetation index from MODIS, respectively. Finally, GPP was estimated with the BNNA method using GCC and vegetation index as inputs at the same time. Compared with eddy covariance GPP, GPP predicted by the BNNA method with GCC and vegetation indices as inputs at the same time showed the highest accuracy of all the experiments. The results indicated that GCC had a higher accuracy than NDVI and EVI when only one vegetation index data was used in the LUE model or the BNNA method. The $\mathrm{R}^{2}$ of GPP estimated by BNNA and GPP from eddy covariance increased by 0.12 on average, RMSE decreased by $1.13 \mathrm{~g} \mathrm{C} \cdot \mathrm{m}^{-2} \cdot$ day $^{-1}$ on average, and MAD decreased by $0.87 \mathrm{~g} \mathrm{C} \cdot \mathrm{m}^{-2} \cdot$ day $^{-1}$ on average compared with GPP estimated by the traditional LUE model and GPP from eddy covariance. This study puts forth a new way to improve the estimation accuracy of GPP on the Tibetan Plateau. With the emergence of a large number of phenological cameras, this method has great potential for use on the Tibetan Plateau, which is heavily affected by clouds and snow.
\end{abstract}

Keywords: green chromatic coordinate; gross primary production; remote sensing; carbon flux; Tibetan Plateau; machine learning

\section{Introduction}

Gross primary production (GPP) refers to the overall photosynthetic fixation of carbon per unit space and time [1]. GPP is extremely important for studying the terrestrial ecosystem carbon cycle and global climate change, because GPP reflects not only the vegetation activity, but also the response of the ecosystem to climate change [2-5]. Therefore, accurately estimating the temporal and spatial 
dynamics of GPP on a regional and global scale is of great significance for understanding the terrestrial ecosystem carbon cycle, assessing grain production, predicting future climate change scenarios and making climate-policy decisions [6-8]. Although there are many GPP models have been developed in the past few decades, it is still a challenging work to accurately estimate daily GPP.

Monteith first proposed the method of estimating vegetation productivity by using photosynthetic effective radiation absorbed by vegetation and established the basis of light use efficiency model [1]. This method is widely used in regional GPP estimation with remote sensing data [9,10]. However, owing to the influence of atmospheric conditions, cloud and sensor degradation, there were large uncertainties in GPP estimated by remote sensing vegetation index data and the light use efficiency (LUE) model [11], such as the CASA model [12], the global production efficiency model (GLO-PEM) [13], the vegetation photosynthesis model (VPM) [14] or the eddy covariance-light use efficiency (EC-LUE) model [15]. However, it is reported that the satellite remote sensing-based GPP contains many problems caused by snow and cloud contaminants and low temporal resolution. For example, GPP was underestimated at the majority of sites in African ecosystems [16] and has unstable performance at various sites $[17,18]$.

Phenological cameras can provide almost time-continuous images at a small spatial scale; meanwhile, they are rarely disturbed by clouds [19-21]. Phenological cameras have the advantages of low cost, small size, convenient installation, and easy handling, and they are widely used to monitor plant dynamics [22]. The phenological camera-based color index was also used to estimate canopy GPP in many studies [23-25]. The performance of GPP estimated by color indexes from phenological camera photos was of varying vegetation types, and the estimation effect of GPP on grassland was better than that of evergreen coniferous forests and deciduous broad-leaved forests [11]. Thus, the phenology camera can provide more reliable daily greenness dynamics and can be fused with satellite remote sensing data to improve daily GPP estimate for alpine meadow ecosystems.

In recent years, data-based machine learning has been widely used in remote sensing data fusion and model integration. Many studies have indicated that machine learning works well in vegetation productivity estimation [26-28]. Machine learning models find rules by training sample data and use these rules to predict unknown results. GPP estimation based on machine learning algorithms can make full use of existing multisource remote sensing data, and they can provide a long time series and high-precision estimation of GPP. Therefore, machine learning has advantage of combining multisource data by machine learning to estimate GPP. The machine learning method predicted GPP with an RMSE of $1.87 \mathrm{~g} \mathrm{C} \cdot \mathrm{m}^{-2} \cdot \mathrm{day}^{-1}$ and an $\mathrm{R}^{2}$ of 0.71 using meteorological and flux data from 33 AmeriFlux sites between 2000 and 2003 in America [29]. The machine learning method was also used to estimate eight days GPP (at the site level) with superior performance on the European spatial scale [30]. Lee successfully estimated the daily GPP of the forest ecosystem using the machine learning method with MODIS data at site scale, and the RMSE reached $1.03 \mathrm{~g} \mathrm{C} \cdot \mathrm{m}^{-2} \cdot \mathrm{day}^{-1}[31]$. These studies mentioned above indicated that the machine learning methods is an effective and widely used method to correctly predict GPP.

The rapid use of phenology cameras in the Tibetan Plateau provides high-quality data that reflect alpine seasonal changes. However, in what extent it can be used to improve GPP estimation for alpine meadows has not been studied. In view of the advantages and disadvantages of phenology camera digital photos and MODIS data, combing digital camera and satellite remote sensing data is an effective way to improve GPP prediction accuracy on the Tibetan Plateau because digital cameras and satellite remote sensing provide complementary information. Thus, the objective of this study are to: (1) compare the performance of color index from phenological photos and vegetation indices from satellite remote sensing data in GPP estimation for alpine meadows on the Tibetan Plateau; (2) compare the performance of the LUE model and a machine learning method in GPP estimation, and (3) explore to what extent the GPP estimation accuracy can be improved by combining multisource remote sensing data for alpine meadows on the Tibetan Plateau. 


\section{Materials and Methods}

\subsection{Study Area}

The Tibetan Plateau is the largest and highest plateau on Earth [32]. The ecosystems of the Tibetan Plateau are sensitive and fragile, and they are sensitive to global climate change. Alpine meadows are a dominant vegetation type on the Tibetan Plateau. The A'rou (AR) eddy covariance (EC) observation station (Figure 1) is located in the eastern part of the Tibetan Plateau. The land surface of the AR station is alpine meadow. The longitude and latitude of the AR station are $100^{\circ} 27^{\prime} 52.9^{\prime \prime} \mathrm{E}$ and $38^{\circ} 02^{\prime} 39.8^{\prime \prime} \mathrm{N}$ and the altitude is $3033 \mathrm{~m}$. The mean annual temperature and annual precipitation are $0.7^{\circ} \mathrm{C}$ and $400 \mathrm{~mm}$, respectively. We divided the seasons on the Tibetan Plateau, with spring as May, summer as June to July, and autumn as August to September [33,34].

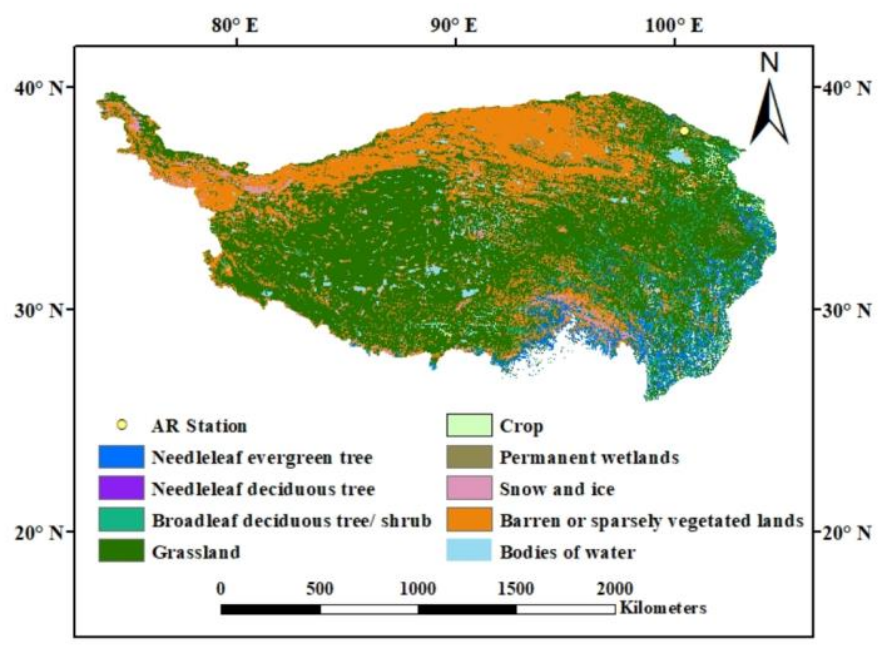

Figure 1. Location of the A'rou (AR) station and vegetation distribution on the Tibetan Plateau.

\subsection{Meteorological Data}

The meteorological data from 2017 to 2018 observed at the AR station were used as input to simulate GPP, including global solar radiation $\left(\mathrm{RG}, \mathrm{w} / \mathrm{m}^{2}\right)$, saturated vapor pressure deficit (VPD, Pa), air temperature $\left(\mathrm{T} \_2 \mathrm{~m}\right.$, air, $\left.{ }^{\circ} \mathrm{C}\right)$ at a height of $2 \mathrm{~m}$ above ground level, and photosynthetically active radiation (PAR, MJ/d/m²). These variables are observed every $10 \mathrm{~min}$, and daily RG, VPD, PAR, and minimum temperature $\left(\mathrm{T}_{\min }\right)$ were calculated from raw $10 \mathrm{~min}$ data in this study (Figure 2).

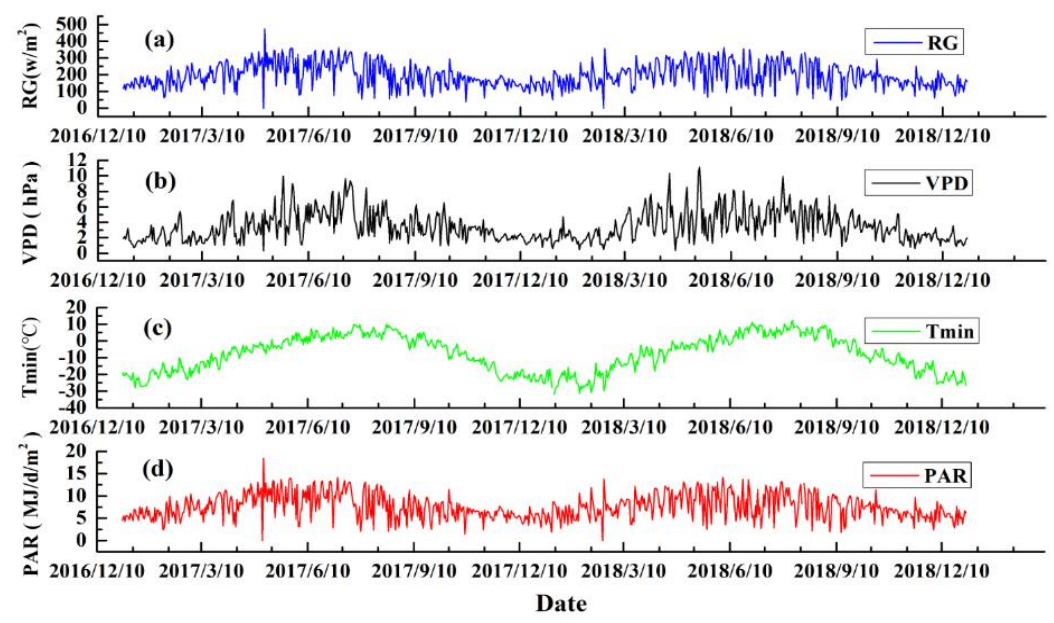

Figure 2. (a) RG, (b) VPD, (c) $\mathrm{T}_{\min }$ and (d) PAR of the A'rou (AR) station on the Tibetan plateau from 2017 to 2018. 


\subsection{Remote Sensing Data}

MOD09GA is the daily MODIS surface reflectance product, which was atmospherically corrected [35]. The band reflectance data of MOD09GA can be obtained from Google Earth Engine (https://earthengine.google.com/) and its spatial resolution and temporal resolution are $250 \mathrm{~m}$ and daily, respectively [36]. The $3 \times 3$ pixels around the AR station were extracted from MOD09GA data (Figure 3). Daily NDVI and EVI were calculated from the reflectance data using the following formulas:

$$
\begin{gathered}
\mathrm{NDVI}=\frac{\rho_{\mathrm{NIR}}-\rho_{\mathrm{RED}}}{\rho_{\mathrm{NIR}}+\rho_{\mathrm{RED}}} \\
\mathrm{EVI}=2.5 \times \frac{\rho_{\mathrm{NIR}}-\rho_{\mathrm{RED}}}{\rho_{\mathrm{NIR}}+6 \times \rho_{\mathrm{RED}}-7.5 \times \rho_{\mathrm{BLUE}}+\mathrm{C}}
\end{gathered}
$$

where $\rho_{\text {RED }}, \rho_{\text {NIR, }}$ and $\rho_{\text {BLUE }}$ are the band reflectance of the red, near-infrared, and blue band, respectively. $C$ is the adjustment parameter, and the value of $C$ is set to 1 .

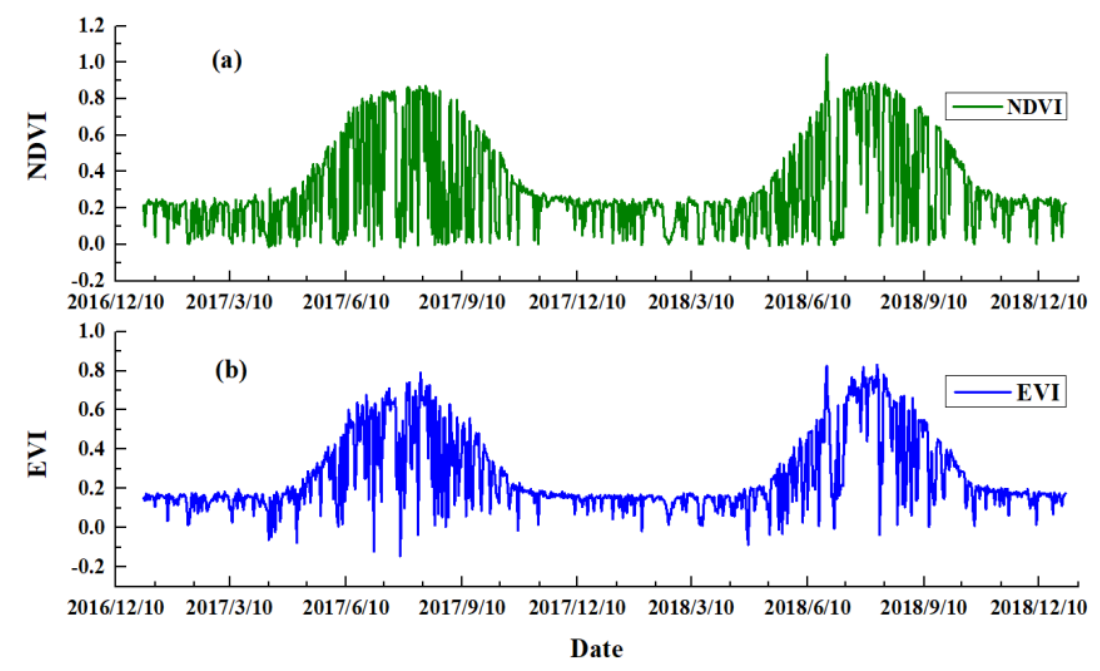

Figure 3. (a) NDVI and (b) EVI of the A'rou (AR) station on the Tibetan plateau from 2017 to 2018.

\subsection{GPP from Eddy Covariance}

GPP data from AR eddy covariance flux site (Figure 1) on the Tibetan Plateau were used to evaluate the GPPs derived from remote sensing data and phenological camera photos. Eddy covariance raw flux data were processed rigidly, including despike, time lag correction, coordinate rotation, frequency response correction, and WPL correction [37]. After gap-filling and partition, daily GPP was calculated based on ecosystem respiration (Re) and net ecosystem exchange (NEE) data by using Equations (3) and (4) [38]:

$$
\begin{gathered}
\mathrm{NEE}=\frac{\varepsilon_{\max } \times \mathrm{PAR} \times \mathrm{GEE}_{\max }}{\varepsilon_{\max } \times \mathrm{PAR}+\mathrm{GEE}_{\max }}-\mathrm{Re} \\
\mathrm{GPP}=\mathrm{NEE}+\mathrm{Re}
\end{gathered}
$$

where $\varepsilon_{\max }$ is the maximum LUE in $\mathrm{g}$ C/MJ APAR, GEEmax is the maximum gross ecosystem exchange in $\mathrm{g} \mathrm{C} / \mathrm{m}^{2} / \mathrm{s}[39]$.

\subsection{Phenological Camera Photos and Color Index Extraction}

Phenological cameras (NV201E digital cameras, Haoxin Netscape Network Technology Co., Ltd., Shenzhen, China) were installed at the AR station on 15th April, 2017. They continually record the surface status by taking photos almost vertically and toward the south to avoid the tower shadow. These phenological cameras took photos with a resolution of $1600 \times 1200$ and can specify the shooting time and frequency (Figure 4). During the observation period, photos were saved in JPEG format. 
These phenological cameras were operated in automatic exposure mode with the white balance adjustment in "automatic mode". In 2017 year, the times the photos were taken were 7:30, 7:45, 8:00, $11: 30,11: 45,12: 00,17: 30,17: 45$, and 18:00. In 2018 year, the time was adjusted and the times were 8:30, $8: 45,9: 00,11: 30,11: 45,12: 00,17: 30,17: 45$, and 18:00 respectively. We deleted the photos when the light was too strong or too weak from the photo set, so as to get the photos of real recorded features under normal weather conditions. The green chromatic coordinate (GCC) was calculated to reflect the canopy greenness, which was widely used to monitor canopy development and was strongly related to GPP $[40,41]$. GCC was calculated using following formulas:

$$
\begin{gathered}
\mathrm{GCC} 1=\frac{\mathrm{DN}_{\mathrm{G}}}{\mathrm{DN}_{\mathrm{R}}+\mathrm{DN}_{\mathrm{G}}+\mathrm{DN}_{\mathrm{B}}} \\
\mathrm{GCC} 2=\frac{\mathrm{DN}_{\mathrm{G}}}{\mathrm{DN}_{\mathrm{R}}+\mathrm{DN}_{\mathrm{B}}}
\end{gathered}
$$

where DN is the digital number and R, G, and B were the pixel values of red, green, and blue channels, respectively. GCC1 and GCC2 are both green chromatic coordinate (GCC), but the denominators in the calculation Equations (5) and (6) were different.
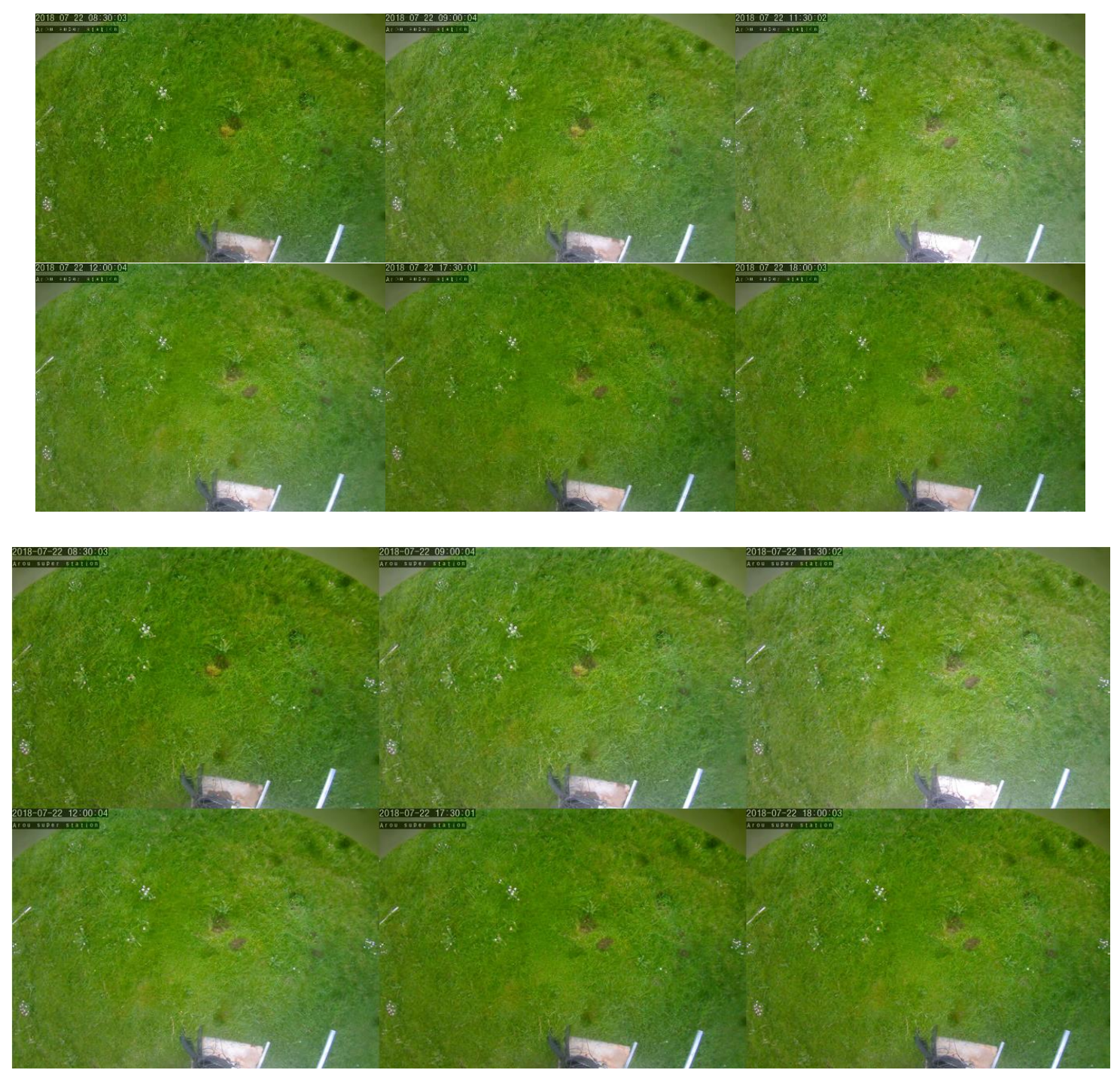

Figure 4. Example photos at different moments of the day by the phenological camera at A'rou (AR) station on 22 July 2018. 
To ensure the reliability of GCC data, we set some conditions on the quality of the photos as following: (1) Make sure that there were no underexposed photos. (2) No shadows of the the flux tower appeared in the photos. (3) No obvious animals and people appeared in the photos. We extracted digital RGB data from the ROI $(400 \times 600)$ of the images and calculated GCC1 and GCC2 for all photos. We found that the $\mathrm{R}^{2}$ of ROI_GCC1 and GPP from eddy covariance were higher than the $\mathrm{R}^{2}$ of ROI_GCC2 and GPP from eddy covariance (Figure 5), so ROI_GCC1 was used for all GPP estimations in this study.
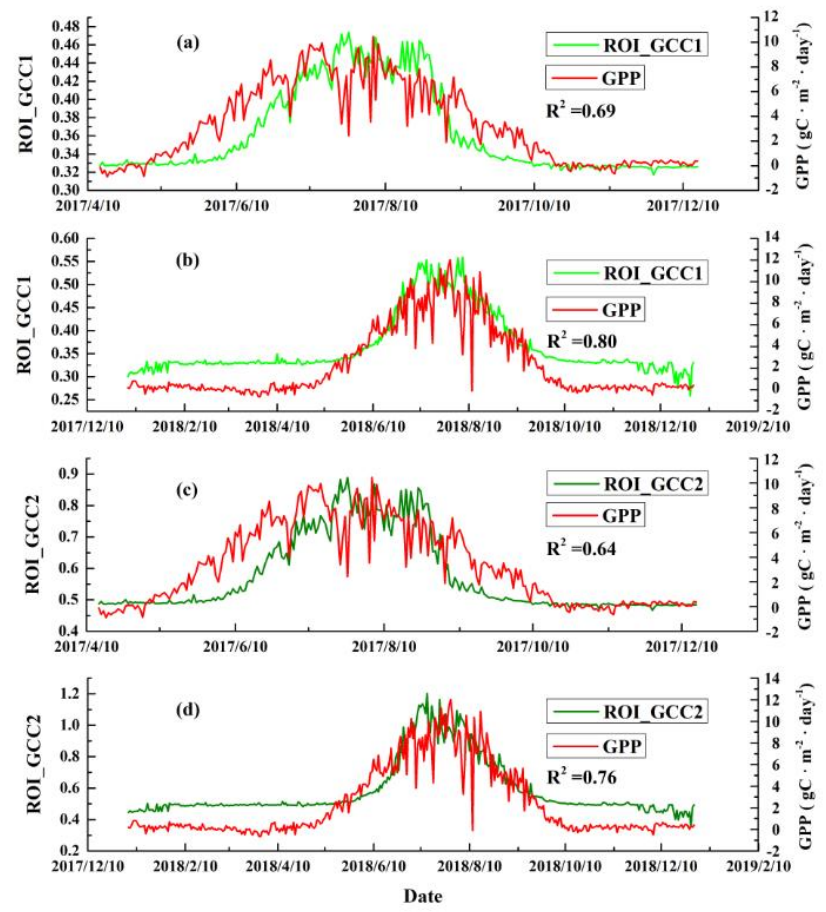

Figure 5. Changes of ROI_GCC1 (a,b) and ROI_GCC2 (c,d) with GPP from eddy covariance, time from (a) 15 April to 16 December, 2017, (b) from 5 January to 31 December 2018, (c) from 15 April to 16 December 2017, and (d) from 5 Januaryto 31 December 2018.

2.6. GPP Model Based on VIs and GCC

The LUE model was used in study to estimate GPP, as follows:

$$
\begin{gathered}
\mathrm{GPP}_{\text {model }}=\varepsilon \times \mathrm{FPAR} \times \mathrm{PAR} \\
\varepsilon=\varepsilon_{\text {max }} \times \mathrm{f}(\text { Tmin }) \times \mathrm{f}(\mathrm{VPD}) \\
\mathrm{FPAR}=\alpha \times \mathrm{NDVI} \\
\mathrm{FPAR}=\alpha \times \mathrm{EVI} \\
\mathrm{FPAR}=\alpha \times \mathrm{CI}_{\text {norm }}
\end{gathered}
$$

where $\varepsilon$ is light use efficiency in photosynthesis ( $\mathrm{g} \mathrm{C} / \mathrm{MJ})$ and PAR $\left(\mathrm{MJ} / \mathrm{d} / \mathrm{m}^{2}\right)$ is photosynthetically active radiation. PAR $=n \times R G$. $n$ is the proportion of PAR in the global total solar radiation and was not a fixed value. For calculations, $\mathrm{n}=0.45$ was used. FPAR is the fraction of absorbed photosynthetically active radiation by vegetation. In this study, FPAR was estimated from the normalized color index $\left(\mathrm{CI}_{\text {norm }}\right)$ of GCC, NDVI and EVI by Equations (9)-(11). $\alpha$ is the coefficient constant and is assumed to be 1.0 [14]. The value of $\varepsilon_{\max }$ was set to $1.6 \mathrm{~g} \mathrm{C} \cdot \mathrm{m}^{-2} \cdot \mathrm{day}^{-1} \cdot \mathrm{MJ}^{-1}$ according to literature for alpine meadow [39]. 
$f\left(T_{\min }\right)$ and $f(V P D)$ are simple linear piecewise slope functions of daily minimum temperature $\left(T_{\min }\right)$ and daily average VPD [42]. $f\left(T_{\min }\right)$ and $f(V P D)$ reflect the environmental stress on vegetation photosynthesis and are expressed as:

$$
\begin{array}{r}
f(T \min )=\left\{\begin{array}{lr}
0, & T \text { min }<\mathrm{Tmin}_{\min } \\
\frac{\mathrm{Tmin}_{\min }-\mathrm{Tmin}_{\min }}{\mathrm{Tm}_{\min }-\mathrm{Tmin}_{\min },} & \mathrm{Tmin}_{\min }<\mathrm{Tmin}<\mathrm{Tmin}_{\max } \\
1, & \mathrm{Tmin}>\mathrm{Tmin}_{\max }
\end{array}\right. \\
\mathrm{f}(\mathrm{VPD})=\left\{\begin{array}{lr}
0, & \mathrm{VPD}>\mathrm{VPD}_{\max } \\
\frac{\mathrm{VPD}_{\max }-\mathrm{VPD}}{\mathrm{VPD}_{\max }-\mathrm{VPD}_{\min },} & \mathrm{VPD}_{\min }<\mathrm{VPD}<\mathrm{VPD}_{\max } \\
1, & \mathrm{VPD}<\mathrm{VPD}_{\min }
\end{array}\right.
\end{array}
$$

where $\mathrm{VPD}_{\max }, \mathrm{VPD}_{\min }, \mathrm{Tmin}_{\max }$, and $\mathrm{Tm}_{\min }$ min are model parameters and the values were from the default parameters for grass in the BPLUT table [43].

The GCC values of RGB color photos of the AR station from 2017 to 2018 were calculated in Python 3.5, and the $\mathrm{CI}_{\text {norm }}$ index was calculated with the GCC values (Equation (14)). The $\mathrm{CI}_{\max }$ and $\mathrm{CI}_{\min }$ were the maximum and minimum value of GCC in each year, respectively. The GPPs based on $\mathrm{CI}_{\text {norm }}$ and the remote sensing VIs was conducted by Equations (15)-(17), and the equations are given by:

$$
\begin{aligned}
\mathrm{CI}_{\text {norm }} & =\frac{\mathrm{CI}-\mathrm{CI}_{\text {min }}}{\mathrm{CI}_{\text {max }}-\mathrm{CI}_{\text {min }}} \\
\mathrm{GPP}_{\text {model }} & =\varepsilon \times \mathrm{CI}_{\text {norm }} \times \mathrm{PAR} \\
\mathrm{GPP}_{\text {model }} & =\varepsilon \times \mathrm{NDVI} \times \mathrm{PAR} \\
\mathrm{GPP}_{\text {model }} & =\varepsilon \times \mathrm{EVI} \times \mathrm{PAR}
\end{aligned}
$$

\subsection{BP Neural Network Algorithm}

The BP neural network is a multilayer feedforward network trained by error back propagation. The BP neural network algorithm (BNNA) contains an input layer, hidden layer, and output layer, and each layer includes a specific number of neurons. We chose BNNA for this study because it had the following four capabilities: 1 . BNNA has a strong nonlinear mapping ability; 2 . BNNA has a highly self-learning and self-adaptive ability; 3 . BNNA has the ability to apply learning results to new knowledge; 4. BNNA has a certain fault tolerance. We used Keras based on TensorFlow high-level Application Programming Interface (Google Artificial Intelligence Team Google Brain, Mountain view, Santa Clara County, CA, USA) and BNNA to achieve machine learning fusion of meteorological data, MOD09GA VIs, and phenological cameras GCC to predict GPP. First, the input datasets were normalized and mapped to the range [0,1], and then BNNA was trained with data in 2017. Training was stopped when BNNA reached the iteration stop condition (Terror $=1 \times 10^{-7}$ ) and number of iterations (epochs $=100$ ). The data in 2018 were used to validate the BNNA to test the performance of established model. $\mathrm{R}^{2}$, RMSE, Mean Absolute Deviation (MAD) indices between the GPP from eddy covariance and simulated GPP were calculated to evaluate the accuracy during training and validation periods. The structure and key parameters of BNNA are reported in Figure 6 and Table 1. The process of machine learning GPP modeling consisted of four groups of experiments (Table 2).

Too many or too few iterations of the training model in the BNNA will cause uncertainty in training errors. Only repeated experiments can sum up a relatively minimum number of trainings and obtain better training results. Finally, we set $\mathrm{n}=100$. If the activation function was not set properly, the BP neural network will not converge. We compared the convergence effects of different activation functions and found that the effects of the "tanh" activation was better than others for the training. The learning rate was generally set to 0.1 for BNNA. 


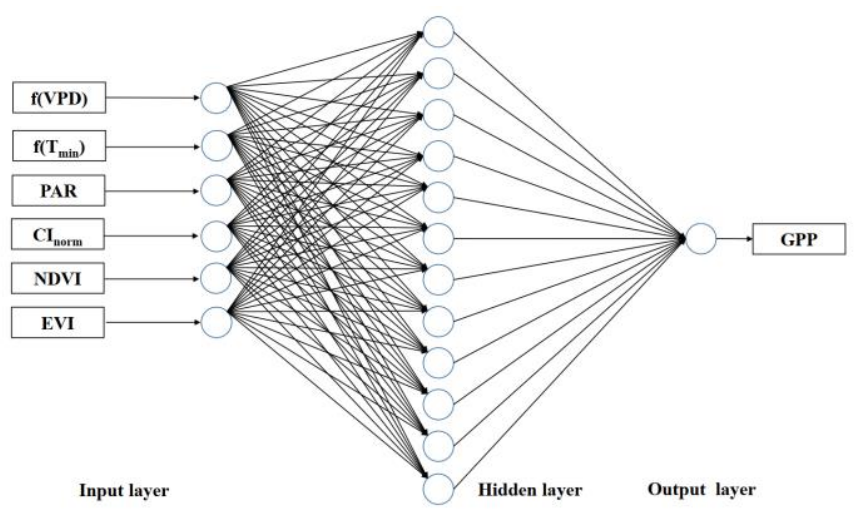

Figure 6. Structure of the BP neural network algorithm.

Table 1. The parameter settings in the BP neural network algorithm.

\begin{tabular}{cc}
\hline Parameters and Values & Explanatory Notes \\
\hline epochs $=100$ & Number of iterations \\
batch_size $=6$ & Number of feeding data for each training model \\
learnrate $=0.1$ & Learning rate \\
Activation $=$ "tanh" & Activation function \\
Terror $=1 \times 10^{-7}$ & Iteration stop condition \\
Loss $=$ 'mean_squared_error' & Loss function \\
Dropout $=0.2$ & Rejection rate of each layer \\
model & Hierarchical model \\
\hline
\end{tabular}

Table 2. Machine learning-based GPP estimation experiments.

\begin{tabular}{ccc}
\hline Experiments & Input Layer & Output Layer \\
\hline Exp 1 & $\mathrm{f}(\mathrm{VPD}), \mathrm{PAR}, \mathrm{f}\left(\mathrm{T}_{\min }\right), \mathrm{CI}_{\text {norm }}$ & $\mathrm{GPP}$ \\
Exp 2 & $\mathrm{f}(\mathrm{VPD}), \mathrm{PAR}, \mathrm{f}\left(\mathrm{T}_{\min }\right), \mathrm{NDVI}$ & $\mathrm{GPP}$ \\
Exp 3 & $\mathrm{f}(\mathrm{VPD}), \mathrm{PAR}, \mathrm{f}\left(\mathrm{T}_{\min }\right), \mathrm{EVI}$ & $\mathrm{GPP}$ \\
Exp 4 & $\mathrm{f}(\mathrm{VPD}), \mathrm{PAR}, \mathrm{f}\left(\mathrm{T}_{\min }\right), \mathrm{CI}_{\text {norm }}, \mathrm{NDVI}, \mathrm{EVI}$ & $\mathrm{GPP}$ \\
\hline & GPP refers to the GPP from eddy covariance.
\end{tabular}

\subsection{Model Output Accuracy Evaluation}

We calculated the $\mathrm{R}^{2}$, RMSE, and MAD in this study to evaluate the performances of the GPPs (GPP_NDVI, GPP_EVI, GPP_CI ${ }_{\text {norm }}$ ) estimated by the remote sensing GPP model and the GPPs (GPP_train1, GPP_train2, GPP_train3, GPP_train4, GPP_valid1, GPP_valid2, GPP_valid3, GPP_valid4) estimated by the BNNA (Figure 7).

$\mathrm{P}$ and $\mathrm{O}$, represent the GPP simulation values and the GPP from eddy covariance, respectively, and $i$ and $n$ represent the days of the year and the total number of days in the year, respectively. The $R^{2}$, RMSE, and MAD are expressed as follows:

$$
\begin{gathered}
\mathrm{R}^{2}=1-\frac{\sum_{\mathrm{i}=1}^{\mathrm{n}}\left(\mathrm{P}_{\mathrm{i}}-\mathrm{O}_{\mathrm{i}}\right)^{2}}{\sum_{\mathrm{i}=1}^{\mathrm{n}} \mathrm{O}_{\mathrm{i}}{ }^{2}} \\
\mathrm{RMSE}=\sqrt{\frac{1}{\mathrm{n}} \sum_{\mathrm{i}=1}^{\mathrm{n}}\left(\mathrm{P}_{\mathrm{i}}-\mathrm{O}_{\mathrm{i}}\right)^{2}} \\
\text { MAD }=\frac{\sum_{\mathrm{i}=1}^{\mathrm{n}}\left|\mathrm{P}_{\mathrm{i}}-\mathrm{O}_{\mathrm{i}}\right|}{\mathrm{n}}
\end{gathered}
$$




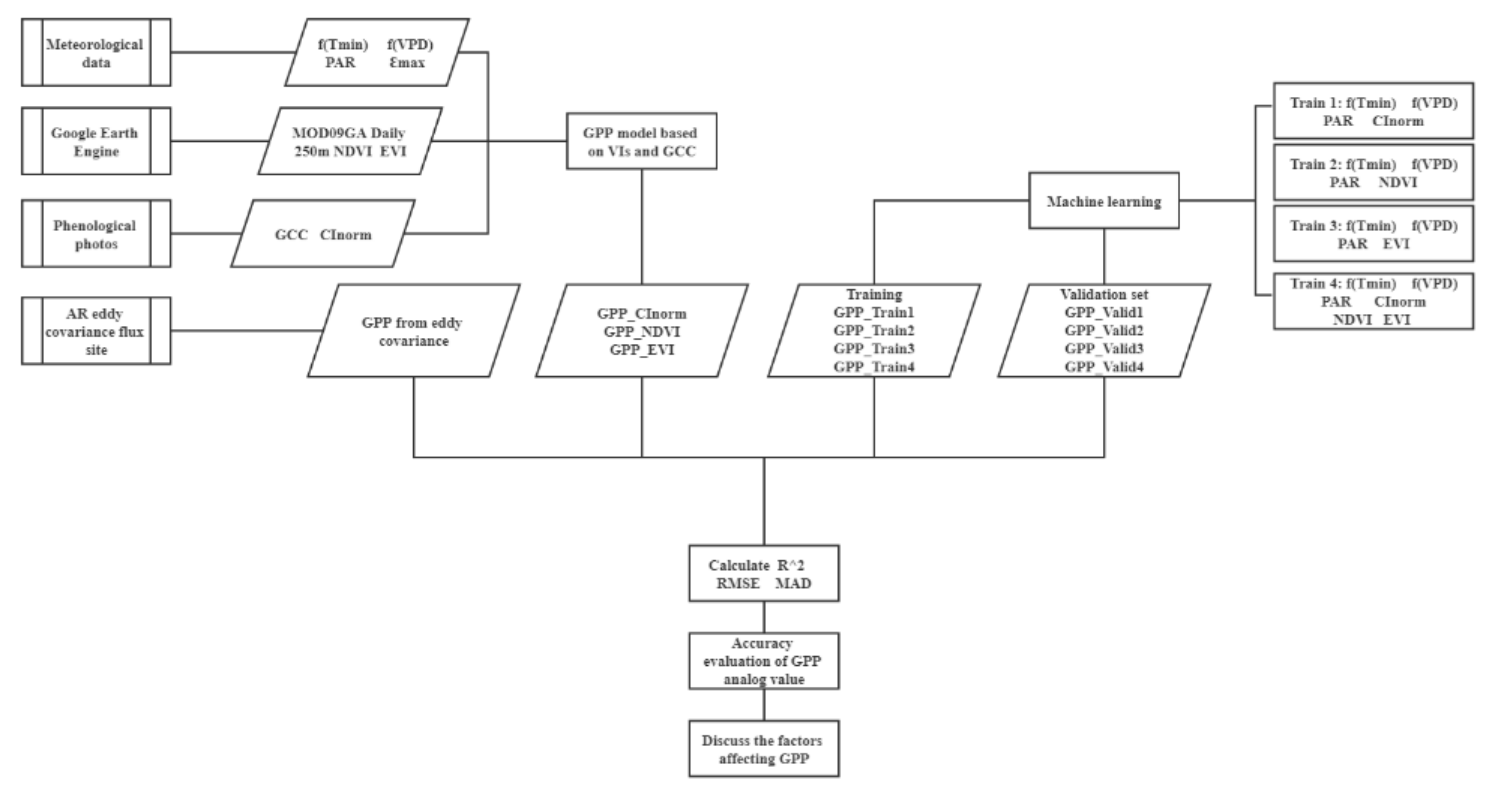

Figure 7. Flow diagram of data processing and analyses.

\section{Results}

\subsection{Simulating GPP with GCC}

The seasonal GPP dynamics estimated from GCC are shown in Figures 8 and A1. The total growing season GPP was $790.48 \mathrm{~g} \mathrm{C} \cdot \mathrm{m}^{-2} \cdot$ day $^{-1}$ in 2017 and $809.24 \mathrm{~g} \mathrm{C} \cdot \mathrm{m}^{-2} \cdot$ day $^{-1}$ in 2018 , respectively. Generally, GPP_CI $I_{\text {norm }}$ showed the same seasonal dynamics with the GPP from eddy covariance in 2017 and 2018. The $\mathrm{R}^{2}$, MAD, and RMSE of GPP_CI $\mathrm{I}_{\text {norm }}$ and the GPP from eddy covariance in the

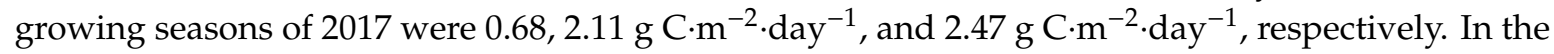

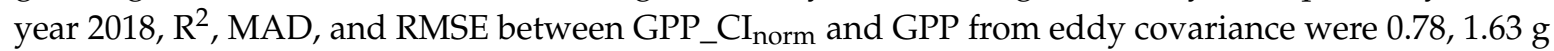
$\mathrm{C} \cdot \mathrm{m}^{-2} \cdot \mathrm{day}^{-1}$, and $1.94 \mathrm{~g} \mathrm{C} \cdot \mathrm{m}^{-2} \cdot \mathrm{day}^{-1}$, respectively. There was a systematic deviation between GPP from GCC and GPP from EC in spring and autumn, and these phenomena appeared both in 2017 and

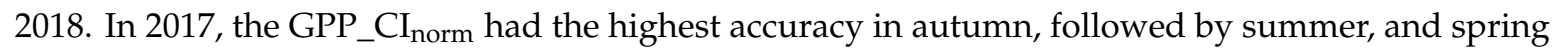
was the worst in the LUE model (Table 3).

In 2018, the GPP_CI norm had the highest accuracy in summer, followed by autumn, and spring was the worst in the LUE model (Table 3). More information about the changes of GPP from eddy covariance and GPP_CI norm in 2017 and 2018 can be found in the appendix (Appendix A, Figure A1).

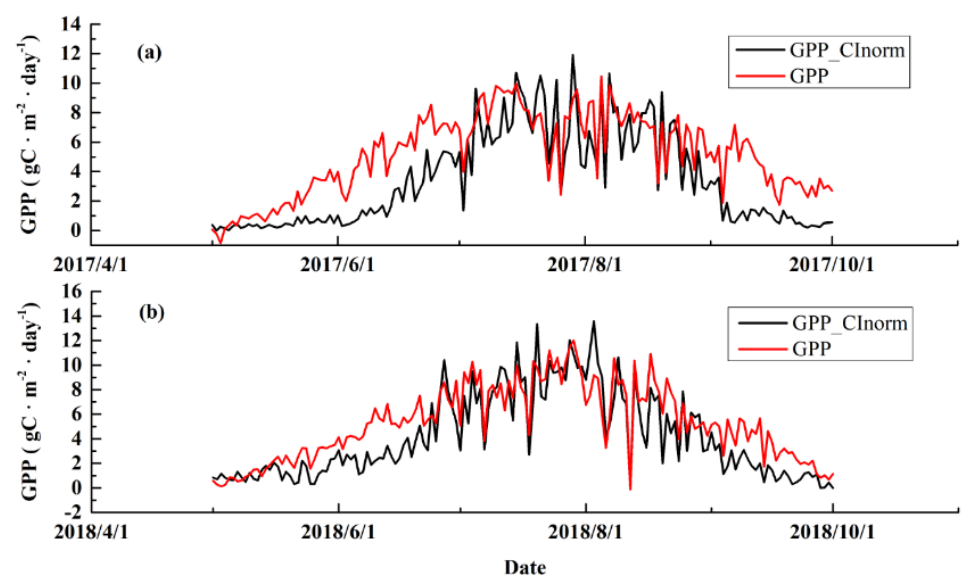

Figure 8. The daily dynamics of the GPP_CI $I_{\text {norm }}$ and the GPP from eddy covariance during the growing seasons (1 May to 1 October), (a) 2017, (b) 2018. 
Table 3. Statistical indicators of the GPP from eddy covariance with the GPP simulation values of remote sensing GPP model in spring, summer, and autumn.

\begin{tabular}{cccccccc}
\hline & GPP & \multicolumn{2}{c}{$\mathbf{R}^{2}$} & \multicolumn{2}{c}{ RMSE } & \multicolumn{2}{c}{ MAD } \\
\hline \multirow{4}{*}{ GPP_CInorm } & Spring & 2017 & 2018 & 2017 & 2018 & 2017 & 2018 \\
& Summer & 0.53 & 0.38 & 1.56 & 1.16 & 1.24 & 0.95 \\
& Autumn & 0.70 & 0.75 & 2.77 & 2.07 & 2.44 & 1.80 \\
& Spring & 0.32 & 0.24 & 2.55 & 2.16 & 2.20 & 1.88 \\
GPP_NDVI & Summer & 0.29 & 0.34 & 3.80 & 4.07 & 2.94 & 3.12 \\
& Autumn & 0.36 & 0.49 & 3.52 & 3.10 & 2.84 & 2.46 \\
& Spring & 0.51 & 0.38 & 0.88 & 1.25 & 0.61 & 0.99 \\
GPP_EVI & Summer & 0.42 & 0.49 & 3.18 & 3.46 & 2.57 & 2.82 \\
& Autumn & 0.49 & 0.57 & 3.14 & 2.76 & 2.61 & 2.23 \\
\hline
\end{tabular}

GPP refers to the GPP from eddy covariance. The seasons on the Tibetan Plateau, with spring as May, summer as June to July, and autumn as August to September.

\subsection{Simulating GPP with MOD09GA VIs}

The comparison between GPP from MODIS NDVI and GPP from eddy covariance in 2017 and 2018 at the AR station are shown in Figure 9a,b. In the growing season of 2017, the $\mathrm{R}^{2}$, RMSE, and MAD between GPP_NDVI and GPP from eddy covariance were $0.36,3.30 \mathrm{~g} \mathrm{C} \cdot \mathrm{m}^{-2} \cdot \mathrm{day}^{-1}$, and $2.46 \mathrm{~g}$ $\mathrm{C} \cdot \mathrm{m}^{-2}$. day ${ }^{-1}$ respectively. In 2017 growing season, the GPP_NDVI had the highest accuracy in autumn, followed by spring and summer (Table 3). The $\mathrm{R}^{2}$, RMSE, and MAD between GPP_NDVI and GPP from eddy covariance were $0.46,3.29 \mathrm{~g} \mathrm{C} \cdot \mathrm{m}^{-2} \cdot \mathrm{day}^{-1}$, and $2.45 \mathrm{~g} \mathrm{C} \cdot \mathrm{m}^{-2} \cdot$ day $^{-1}$ in the growing season of 2018, respectively. In 2018, the GPP_NDVI had the highest accuracy in autumn, followed by summer and spring (Table 3).

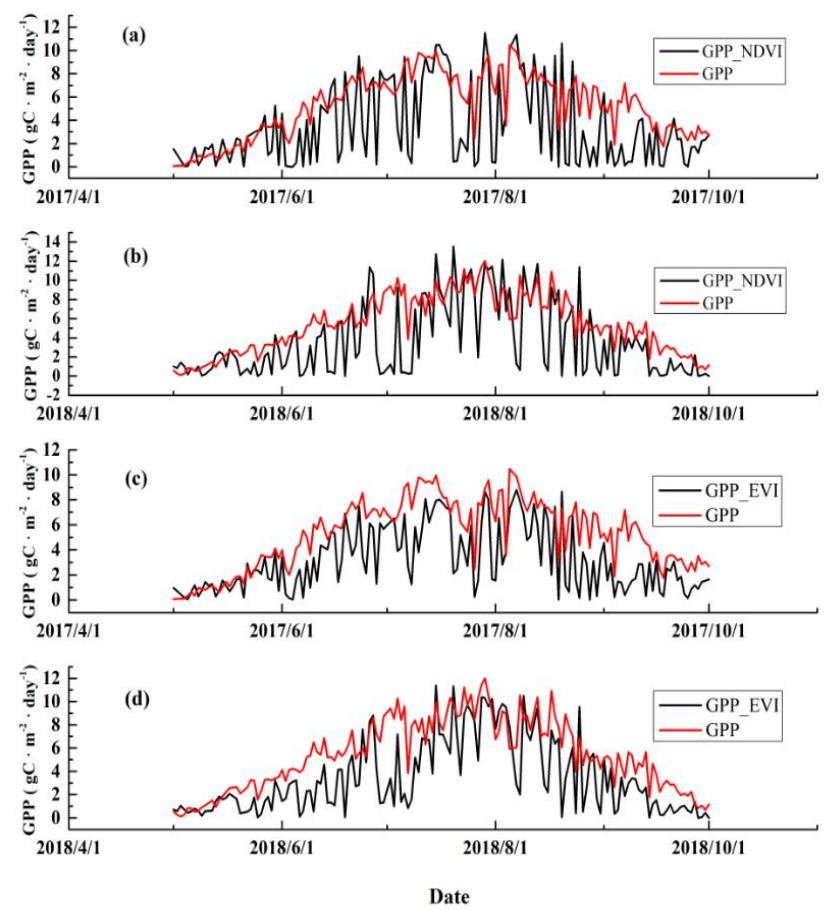

Figure 9. The daily dynamics of the GPP_NDVI, GPP_EVI and the GPP from eddy covariance during the growing seasons (1 May to 1 October), (a) 2017, (b) 2018, (c) 2017, and (d) 2018.

The comparison between GPP from MODIS EVI and GPP from eddy covariance in 2017 and 2018 at the AR station are shown in Figure 9c,d. In the 2017 growing season, the $\mathrm{R}^{2}$, RMSE, and MAD of GPP_EVI and GPP from eddy covariance were $0.53,2.84 \mathrm{~g} \mathrm{C} \cdot \mathrm{m}^{-2} \cdot \mathrm{day}^{-1}$, and $2.19 \mathrm{~g} \mathrm{C} \cdot \mathrm{m}^{-2} \cdot \mathrm{day}^{-1}$, 
respectively. The LUE model with EVI as input (GPP_EVI) had the highest accuracy in spring, followed by autumn and summer (Table 3). During growing season in 2018, the $\mathrm{R}^{2}$, RMSE, and MAD of GPP_EVI and GPP from eddy covariance were $0.59,2.85 \mathrm{~g} \mathrm{C} \cdot \mathrm{m}^{-2} \cdot \mathrm{day}^{-1}$, and $2.22 \mathrm{~g} \mathrm{C} \cdot \mathrm{m}^{-2} \cdot$ day $^{-1}$, respectively. The LUE model with EVI as input (GPP_EVI) performed best in autumn, followed by summer and spring (Table 3).

GPPs estimated from MODIS NDVI (GPP_NDVI) and EVI (GPP_EVI) were able to successfully capture the season dynamics of GPP from eddy covariance (Figure $9 a-d$ ). However, throughout the growing season, daily GPP_NDVI/GPP_EVI was dramatically underestimated at some dates comparing with GPP from eddy covariance, this was mainly caused by cloud or snow contamination of the satellite remote sensing data. The number of cloud contaminated data during the growing season in 2017 was 56, and 49 in 2018. The cumulative MAD caused by GPP_NDVI and GPP_EVI were

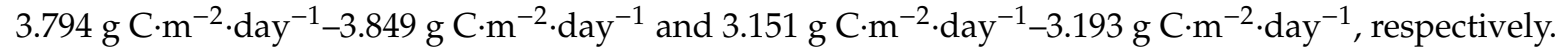
More information about the changes of GPP from eddy covariance and GPP_NDVI and GPP_EVI in two years (2017 and 2018) can be found in the appendix (Appendix A, Figure A2).

\subsection{Simulating GPP with Multisource Data Using Machine Learning}

In machine learning GPP estimation experiment, data in 2017 were used for training, and data in 2018 were used for validation. Four experiments were designed to test the contribution of different input datasets. The time period of the four GPP training experiments was from 26 April to 30 September, 2017. The time period of the four GPP validation experiments was from 26 April to 30 September, 2018. Figures $10 \mathrm{a}-\mathrm{d}$ and $11 \mathrm{a}-\mathrm{d}$ are the results of training and validation in machine learning Exp. 1, Exp. 2, Exp. 3 and Exp. 4, respectively.

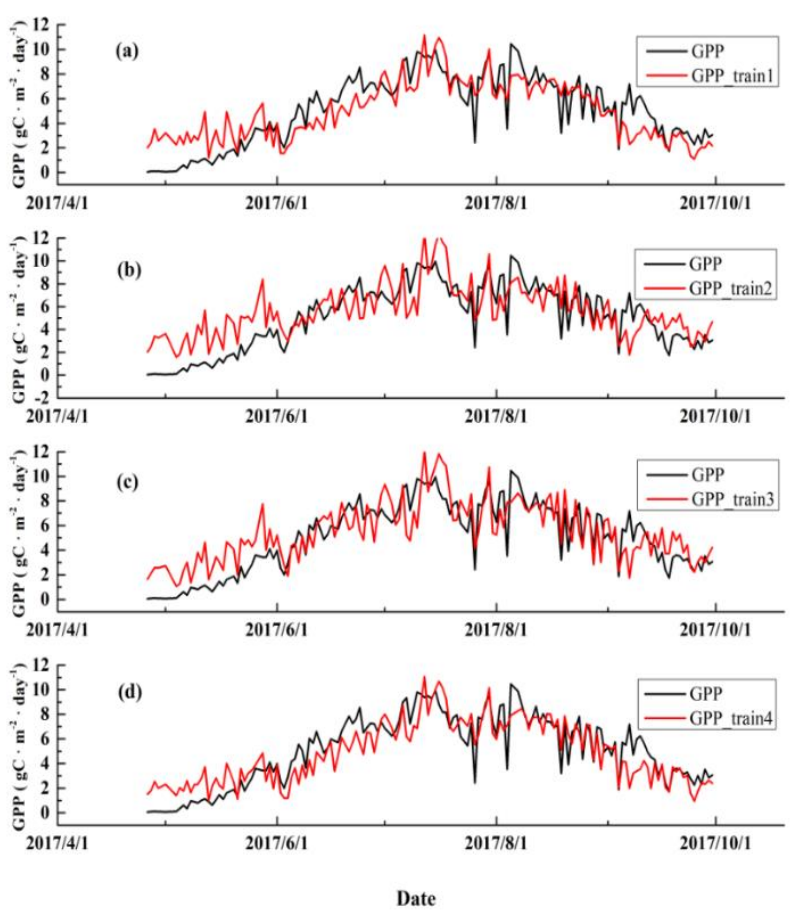

Figure 10. Training results of the four experiments for the BNNA method. (a), (b), (c) and (d) represent the predicted GPP and the GPP from eddy covariance in GPP_train1, GPP_train2, GPP_train3, and GPP_train4, respectively.

During the growing season, autumn had the highest training accuracy, followed by summer and spring corresponding to GPP_train1. For the GPP_train2, spring had the highest training accuracy, followed by autumn and summer. In the GPP_train3 experiment, spring had the highest training accuracy, followed by summer and autumn. In the GPP_train4 experiment, autumn had the highest 
training accuracy, followed by summer and spring (Table 4). In the four validation experiments (Figure 11), it is found that autumn had the highest validation accuracy for all of these experiments (GPP_valid1, GPP_valid2, GPP_valid3 and GPP_valid4), followed by summer and spring.

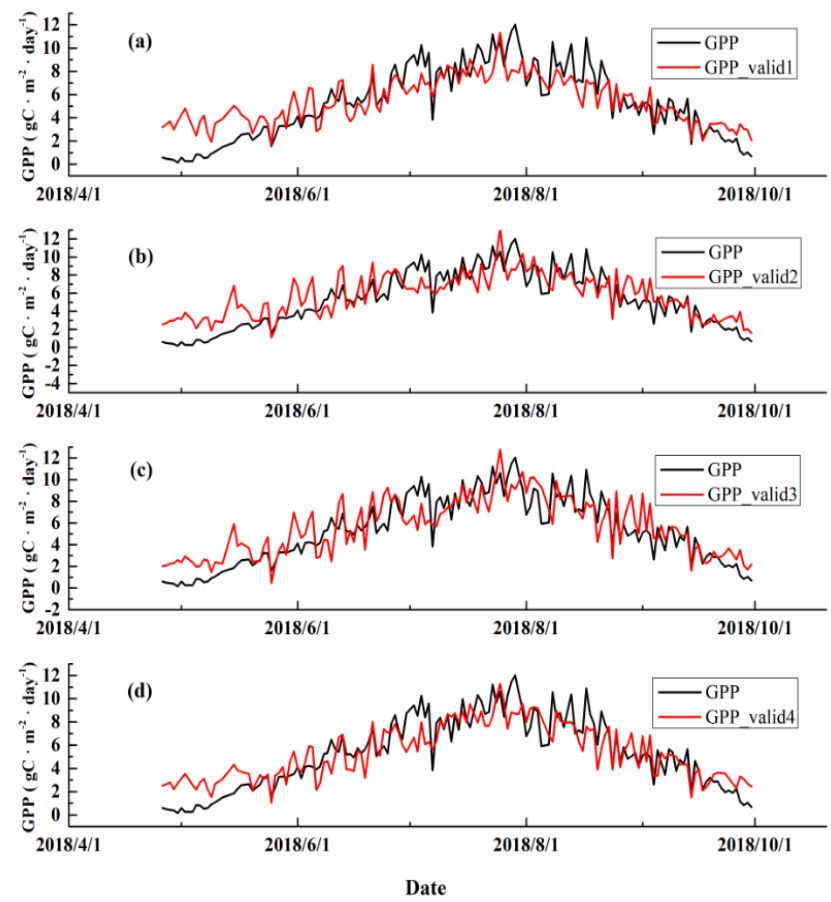

Figure 11. Validation of the four experiments for BNNA method. (a), (b), (c), and (d) represent the year-round changes of GPP_valid and the GPP from eddy covariance in GPP_valid1, GPP_valid2, GPP_valid3, and GPP_valid4, respectively.

Table 4. Statistical indicators of the GPP from eddy covariance with the GPP simulation of the remote sensing GPP model in spring, summer, and autumn.

\begin{tabular}{cccccccc}
\hline \multirow{2}{*}{ Experiment } & \multirow{2}{*}{ Season } & \multicolumn{3}{c}{$\mathbf{R}^{\mathbf{2}}$} & \multicolumn{2}{c}{ RMSE } & \multicolumn{2}{c}{ MAD } \\
\cline { 3 - 8 } & & Training & Validation & Training & Validation & Training & Validation \\
\hline \multirow{3}{*}{1} & Spring & 0.17 & 0.15 & 1.90 & 2.22 & 1.64 & 1.90 \\
& Summer & 0.64 & 0.58 & 1.50 & 1.61 & 1.19 & 1.27 \\
& Autumn & 0.66 & 0.78 & 1.48 & 1.31 & 1.12 & 1.03 \\
\hline \multirow{2}{*}{2} & Spring & 0.53 & 0.29 & 2.62 & 2.18 & 2.38 & 1.83 \\
& Summer & 0.42 & 0.35 & 1.80 & 1.90 & 1.45 & 1.59 \\
& Autumn & 0.43 & 0.69 & 1.66 & 1.48 & 1.35 & 1.16 \\
\hline \multirow{2}{*}{3} & Spring & 0.60 & 0.37 & 2.10 & 1.67 & 1.87 & 1.35 \\
& Summer & 0.48 & 0.41 & 1.69 & 1.86 & 1.39 & 1.56 \\
& Autumn & 0.47 & 0.65 & 1.63 & 1.63 & 1.26 & 1.26 \\
\hline \multirow{2}{*}{4} & Spring & 0.36 & 0.30 & 1.37 & 1.58 & 1.20 & 1.33 \\
& Summer & 0.66 & 0.58 & 1.51 & 1.62 & 1.23 & 1.30 \\
& Autumn & 0.66 & 0.70 & 1.43 & 1.41 & 1.00 & 1.09
\end{tabular}

1, 2, 3, and 4 refer to Exp. 1, Exp. 2, Exp. 3, and Exp. 4, respectively. The seasons on the Tibetan Plateau, with spring as May, summer as June to July, and autumn as August to September. Training refers to the training period (from 26 April to 30 September 2017), Validation refers to the validation period (from 26 April to 30 September 2018).

\subsection{Comparing the Performance of Different GPP Estimation Methods}

The statistical indicators of GPPs estimated by MOD09GA and GCC according to the LUE model and BNNA are shown in Table 5. The seasonal patterns between the GPP from eddy covariance and 
GPP from machine learning method were generally consistent, except for some large fluctuations between May and June. We compared the $\mathrm{R}^{2}$, RMSE, and MAD of the training results of GPP and found that the training accuracy of the GPP_train 4 was the highest followed by GPP_train1, GPP_train3, and GPP_train2. The training accuracy of the GPP_train4 indicated that the training results can be improved by combining multisource data compared with the GPP_train1, GPP_train2, and GPP_train3 in machine learning. In addition, we found that the validation accuracy of GPP_valid4 was the highest followed by GPP_valid1, GPP_valid3, and GPP_valid2. Therefore, the effect of GPP_train4 and GPP_valid4 was the best of machine learning. Among the LUE models forced by different vegetation indices, the model accuracy from high to low were GPP_CI $I_{\text {norm }}$ GPP_EVI, and GPP_NDVI. When compared with the LUE models, the $\mathrm{R}^{2}$, MAD, and RMSE of machine learning were clearly better than those of the LUE models. Therefore, the machine learning method was an effective approach and can significantly improve the simulation accuracy of daily GPP as compared to the LUE model.

Table 5. Statistical indicators of the GPP from eddy covariance with the GPP simulation of the remote sensing GPP model and machine learning from 26 April to 30 September 2017 and from 26 April to 30 September 2018.

\begin{tabular}{cccccc}
\hline & Date/Experiment & GPP & $\mathbf{R}^{\mathbf{2}}$ & MAD & RMSE \\
\hline \multirow{4}{*}{ LUE model } & 2017 & GPP_CInorm & 0.69 & 2.06 & 2.46 \\
& $\mathbf{2 0 1 8}$ & GPP_CI norm & $\mathbf{0 . 7 8}$ & $\mathbf{1 . 6 4}$ & $\mathbf{1 . 9 5}$ \\
& 2017 & GPP_NDVI & 0.37 & 2.45 & 3.29 \\
& 2018 & GPP_NDVI & 0.47 & 2.41 & 3.28 \\
& 2017 & GPP_EVI & 0.54 & 2.18 & 2.83 \\
Machine & Training & GPP_train1 & 0.67 & 1.28 & 1.61 \\
Learning & Training & GPP_train2 & 0.54 & 1.61 & 1.96 \\
Normalized & Training & GPP_train3 & 0.62 & 1.45 & 1.77 \\
& Training & GPP_train4 & $\mathbf{0 . 7 3}$ & $\mathbf{1 . 1 5}$ & $\mathbf{1 . 4 7}$ \\
& Validation & GPP_valid1 & 0.73 & 1.34 & 1.69 \\
& Validation & GPP_valid2 & 0.66 & 1.49 & 1.83 \\
& Validation & GPP_valid3 & 0.69 & 1.41 & 1.74 \\
& Validation & GPP_valid4 & $\mathbf{0 . 7 5}$ & $\mathbf{1 . 2 5}$ & $\mathbf{1 . 5 6}$ \\
\hline
\end{tabular}

2017 (Training) refers to a period (from 26 April to 30 September 2017), 2018 (Validation) refers to a period (from 26 April to 30 September 2018). GPP refers to the GPP from eddy covariance. Bold fields and values are the best performers in LUE model and Machine Learning, respectively.

\section{Discussion}

\subsection{GPP Estimation Based on GCC}

The GCC can be used to quantitatively describe the vegetation canopy greenness in alpine meadows on the Tibetan Plateau, and the $\mathrm{CI}_{\text {norm }}$ derived from GCC can be used to estimate the vegetation GPP. This was consistent with the finding that the GCC can quantify the total GPP of the grassland and deciduous broad-leaved forest [11]. In this study, we found that GPP_CI $\mathrm{I}_{\text {norm }}$ has the highest accuracy, followed by GPP_EVI, and GPP_NDVI was the worst among them. This consequence illustrates that long-term phenological photos can replace remote sensing data thereby obtaining higher-precision regional GPP. In addition, we found that there was no deviation in the GCC peak value obtained from the AR station, but GCC had systematic deviation in spring and autumn. However, previous studies reported that the GCC peak date in growing season is much different from observed GPP in forests and grasslands [21]. The GCC peak value of the phenology photo of the TKY site (deciduous broad-leaved forest) and the TKC site (evergreen coniferous forest) in Japan appeared about 20-30 days before the GPP peaks [26]. GCC and GPP of the Tongyu (meadow steppe) site in the Songnen Plain of China and the Maodeng Ranch (typical steppe) site in Inner Mongolia showed consistent and noticeable seasonal changes. GCC and GPP had large values during the growing season, and the values during the dormant period were very close to zero. The peak of GCC of meadow steppe 
lagged behind the peak of GPP by about ten days, and the peak of GCC of typical steppe lagged behind by GPP by about 20 days [44].

The advantages of GPP estimated by GCC include high continuity of phenology photos and that phenology photos can be obtained multiple times a day with less affects from clouds. In addition, GCC will be affected by some factors when estimating GPP, such as the exposure rate of the photo, the spatial scale of the photo, the height angle of the sun, the presence of shadows or animals in the photo, temperature, and photosynthesis. These factors will affect the values of GCC and thus GPP estimation. To our knowledge, there have been few studies on the use of phenological photos (GCC) to estimate GPP on the Tibetan Plateau. Therefore, the performance of GCC in GPP estimation for alpine meadow on the Tibetan Plateau was tested in this study.

\subsection{GPP Estimation Based on Remote Sensing Vegetation Indices}

The remote sensing data had great advantages of wide coverage and high spatiotemporal resolution, which can be used to estimate GPP for regional and even global over a long period of time. However, the complexity of cloud cover, snow, moisture, temperature, and vegetation growth will all affect the accuracy of GPP estimation by remote sensing [45]. We used the remote sensing vegetation index MOD09GA NDVI and EVI to estimate the GPPs of the AR station on an annual scale. For NDVI, we found that $\mathrm{R}^{2}$ was 0.50 and RMSE was $2.78 \mathrm{~g} \mathrm{C} \cdot \mathrm{m}^{-2} \cdot \mathrm{day}^{-1}$ in $2017 ; \mathrm{R}^{2}$ was 0.57 and RMSE was $2.76 \mathrm{~g} \mathrm{C} \mathrm{m}^{-2} \cdot \mathrm{day}^{-1}$ in 2018 . For EVI, $\mathrm{R}^{2}$ was 0.85 and RMSE was $1.65 \mathrm{~g} \mathrm{C} \cdot \mathrm{m}^{-2} \cdot \mathrm{day}^{-1}$ in $2017 ; \mathrm{R}^{2}$ was 0.87 and RMSE was $1.56 \mathrm{~g} \mathrm{C} \cdot \mathrm{m}^{-2} \cdot \mathrm{day}^{-1}$ in 2018 (Appendix A, Figure A2). Li estimated the GPPs of AR station in 2009 and reported that $R^{2}$ of LUE models were up to 0.8 at AR station at annual scale [46]. This is consistent with the performance of the LUE model in this study. This study found that at the AR station, using EVI to estimate GPP was better than using NDVI. This was also reported by a previous study [47]. Compared with NDVI, the blue band was used to correct the background effects when calculating EVI. This difference may be one of the reasons that EVI had a better correlation with GPP than NDVI [48]. These findings were consistent with conclusions that the remote sensing GPP model can accurately estimate GPP in alpine meadows.

The GPP_NDVI and GPP_EVI estimated by the LUE model based on the MOD09GA vegetation indices fluctuated greatly during the growing seasons, which were lower than the GPP from eddy covariance (Figure 9). GPP_NDVI and GPP_EVI had many cloud contaminated data points close to zero during the growing season, which may be caused by some noise points in the MOD09GA product. For GPP_NDVI, the number of cloud-contaminated data in the growing season of 2017 year was 56, $\mathrm{R}^{2}$ of GPP_NDVI and GPP from eddy covariance was 0.22 , the number of without cloud contaminated data was 92 , and the $\mathrm{R}^{2}$ of GPP_NDVI and GPP from eddy covariance was 0.61 . The number of cloud contaminated data in the growing season of 2018 year was 49 , the $R^{2}$ of GPP_NDVI and GPP from eddy covariance was 0.26 , the number of without cloud contaminated data was 99 , and the $R^{2}$ of GPP_NDVI and GPP from eddy covariance was 0.60 . For GPP_EVI, the number of cloud contaminated data in the growing season of 2017 year was $48, R^{2}$ of GPP_EVI and GPP from eddy covariance was 0.40 , the number of without cloud contaminated data was 100, and the $\mathrm{R}^{2}$ of GPP_EVI and GPP from eddy covariance was 0.64 . The number of cloud contaminated data in the growing season of 2018 year was 46 , the $\mathrm{R}^{2}$ of GPP_EVI and GPP from eddy covariance was 0.43 , the number of without cloud contaminated data was 102, and the $\mathrm{R}^{2}$ of GPP_EVI and GPP from eddy covariance was 0.71 . For the non-growth seasons, because all the alpine grasses were withered and photosynthesis was weak, GPP_NDVI and GPP_EVI were very small and close to zero, which was consistent with the GPP from eddy covariance (Appendix A, Figure A2).

\subsection{The Impact of $\varepsilon_{\max }$ for GPP Estimation}

The maximum light energy utilization rate $\left(\varepsilon_{\max }\right)$ of the remote sensing GPP model is an important parameter and has an important impact on the accuracy of GPP modeling. Turner revealed that the MODIS GPP algorithm may cause $\varepsilon_{\max }$ to be underestimated [49]. MODIS GPP products in the 
midwestern U.S. croplands were underestimated due to the inaccuracy of $\varepsilon_{\max }$ estimation. Therefore, the LUE values measured in the field should be used consistently in large-scale GPP modeling [50]. Lin conducted a monthly parameterization of the one-leaf LUE model and the two-leaf LUE model of eighteen typical plant function types. The results indicated that the $\varepsilon_{\max }$ of most plant function types change with the season and had a significant positive correlation with the leaf area index and environmental temperature changes [17]. Wei developed a data-driven RFR-GPP model using random forest regression method, which showed LUE varied largely with latitude [51]. Zheng examined different sources of uncertainty in GPP simulated by LUE models and found that model structures (e.g., FPAR, Ws, and Ts) influenced both model parameters and model performance [52]. The $\varepsilon_{\max }$ in alpine meadows at different altitudes on the Tibetan Plateau estimated to be $1.83 \mathrm{~g} \mathrm{C} / \mathrm{MJ}$ and $1.33 \mathrm{~g}$ $\mathrm{C} / \mathrm{MJ}[47,53]$. The $\varepsilon_{\max }$ of this study was equal to $1.6 \mathrm{~g} \mathrm{C} / \mathrm{MJ}$ in alpine meadows [39]. $\varepsilon_{\max }$ also vary with spatial and even in different year. Using a constant $\varepsilon_{\max }$ for a certain biome may cause errors in LUE-oriented GPP modeling [54]. Therefore, obtaining reasonable $\varepsilon_{\max }$ is vital to LUE models.

\subsection{BNNA Performance Evaluation for GPP Estimation}

In recent years, machine learning methods have been widely used in GPP estimation for its flexibility in application. In this work, it was found that machine learning algorithm (BNNA) performed well in alpine meadow GPP prediction. The machine learning algorithm (BNNA) was more accurate than the LUE models. The advantages of using machine learning method to fuse multisource data to estimate GPP were that machine learning methods can easily fuse data from different sources together and can combine the advantages of different data for GPP estimation. However, the main shortages were the lack of mechanism process, the need for a large number of training samples, and the results of training in different regions cannot be applied to other regions. The implication of this study was to provide a new idea to improve the GPP estimation accuracy on the Tibetan Plateau. With the large number of phenological cameras, the method will have good application potential on the Tibetan Plateau, which is greatly affected by clouds and snow.

\section{Conclusions}

The GPP_CI $\mathrm{norm}_{\text {has }}$ the highest accuracy, followed by GPP_EVI, and GPP_NDVI was the worst in the LUE model. However, it should be noted that there is a problem with the seasonal dynamics of $\mathrm{CI}_{\text {norm }}$ results, manifested as a significant deviation existing in spring and autumn. In several sets of machine learning experiments, the accuracy of GPP was found to be the highest when both the $\mathrm{CI}_{\text {norm }}$ based on phenological camera photo and MODIS vegetation indices (NDVI and EVI) are input at the same time, indicating that the two types of data can complement each other's defects and improve estimation accuracy of GPP. Compared with the GPP accuracy estimated by EVI and NDVI in the LUE model, the GPP accuracy estimated by combining multisource data is increased by $27 \%$ and $59 \%$, respectively. These results illustrate that the overall accuracy of machine learning is significantly higher than the traditional LUE model. However, compared with the GPP accuracy estimated by $\mathrm{CI}_{\text {norm }}$ in the LUE model, it is reduced by $3 \%$, which is caused by the lower quality of GPP data from eddy covariance and the shorter time series of GCC data. Due to the late installation of phenological camera resulting in the quantity of photos available now is very small. Thus, we can get longer time series GCC data later, the purpose is to reduce the impact of the amount of data on the accuracy of machine learning estimation GPP.

Author Contributions: X.W. designed the research; X.Z., Y.Z., X.B., and X.W. collected and processed data; X.Z. and X.W. analyzed the data and wrote the draft; S.Z. provided import input to the manuscript; X.Z. and X.W. revised the paper. All authors have read and agreed to the published version of the manuscript.

Funding: This work was supported by the National Key R\&D Program of China (Grant No. 2017YFA0604801), the National Natural Science Foundation of China (Grant No. 41771466), the Special Fund for Key Program of Science and Technology of Qinghai Province (Grant No. 2017-SF-A6), and the Youth Innovation Promotion Association CAS to X.W. (No. 2020422). 
Conflicts of Interest: The authors declare no conflict of interest.

\section{Appendix A}

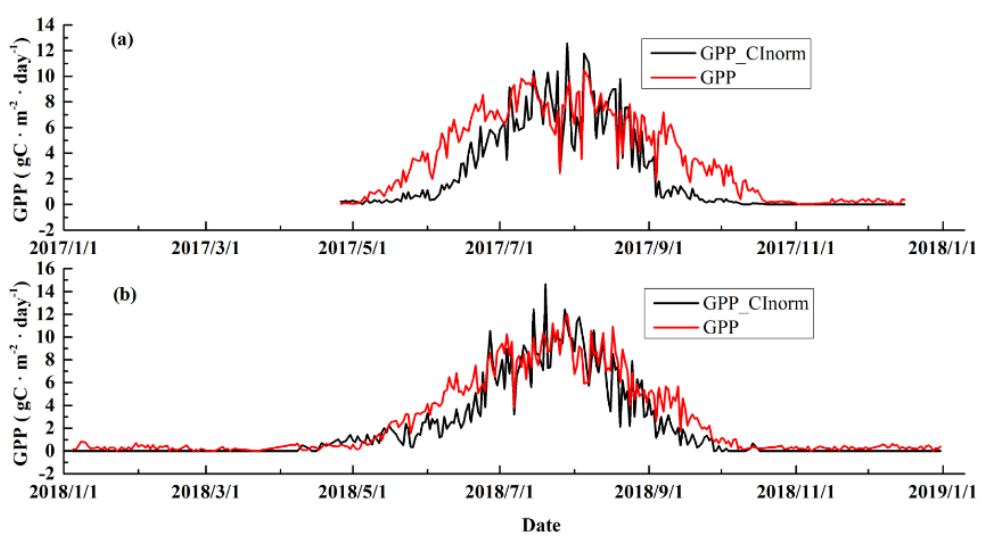

Figure A1. The annual changes of the GPP_CI $\mathrm{I}_{\text {norm }}$ and the GPP from eddy covariance, time from (a) 26 April to 16 December 2017, and (b) from 5 January to 31 December 2018.
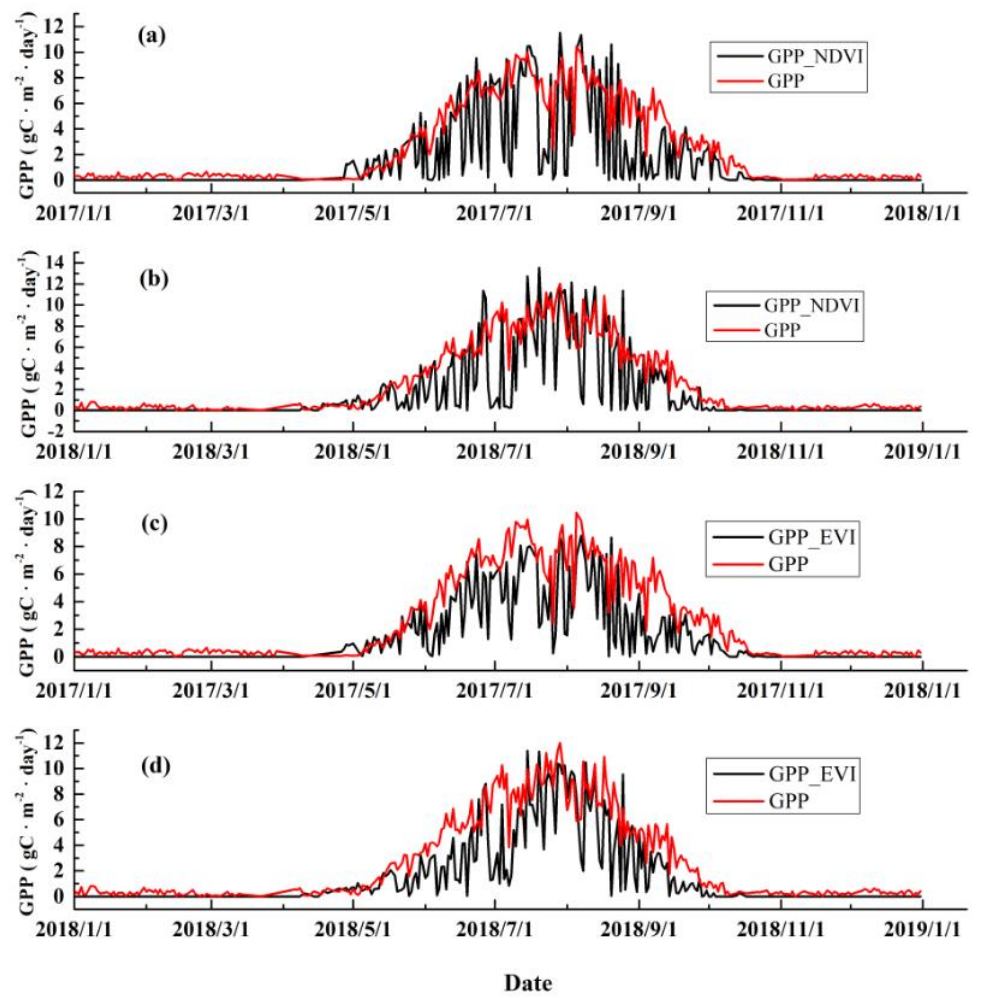

Figure A2. The year-round changes of GPP_NDVI in 2017 (a), GPP_NDVI in 2018 (b), GPP_EVI in 2017 (c), GPP_EVI in 2018 (d) along with the GPP from eddy covariance in the same year.

\section{References}

1. Monteith, J.L. Solar Radiation and Productivity in Tropical Ecosystems. J. Appl. Ecol. 1972, 9, 747-766. [CrossRef]

2. Wang, S.; Huang, K.; Yan, H.; Yan, H.; Zhou, L.; Wang, H.; Zhang, J.; Yan, J.; Zhao, L.; Wang, Y.; et al. Improving the light use efficiency model for simulating terrestrial vegetation gross primary production by the inclusion of diffuse radiation across ecosystems in China. Ecol. Complex. 2015, 23, 1-13. [CrossRef] 
3. Jia, W.; Liu, M.; Wang, D.; He, H.; Shi, P.; Li, Y.; Wang, Y. Uncertainty in simulating regional gross primary productivity from satellite-based models over northern China grassland. Ecol. Indic. 2018, 88, 134-143. [CrossRef]

4. Lobell, D.B.; Hicke, J.A.; Asner, G.P.; Field, C.B.; Tucker, C.J.; Los, S.O. Satellite estimates of productivity and light use efficiency in United States agriculture, 1982-1998. Glob. Chang. Biol 2002, 8, 722-735. [CrossRef]

5. Yu, G.-R.; Zhu, X.-J.; Fu, Y.-L.; He, H.-L.; Wang, Q.-F.; Wen, X.-F.; Li, X.-R.; Zhang, L.-M.; Zhang, L.; Su, W.; et al. Spatial patterns and climate drivers of carbon fluxes in terrestrial ecosystems of China. Glob. Chang. Biol. 2013, 19, 798-810. [CrossRef]

6. Zhang, W.J.; Wang, H.M.; Yang, F.T.; Yi, Y.H.; Wen, X.F.; Sun, X.M.; Yu, G.R.; Wang, Y.D.; Ning, J.C. Underestimated effects of low temperature during early growing season on carbon sequestration of a subtropical coniferous plantation. Biogeosciences 2011, 8, 1667-1678. [CrossRef]

7. Mekonnen, Z.A.; Grant, R.F.; Schwalm, C. Contrasting changes in gross primary productivity of different regions of North America as affected by warming in recent decades. Agric. For. Meteorol. 2016, 218-219, 50-64. [CrossRef]

8. Jahan, N.; Gan, T.Y. Developing a gross primary production model for coniferous forests of northeastern USA from MODIS data. Int. J. Appl. Earth Obs. Geoinf. 2013, 25, 11-20. [CrossRef]

9. Xiao, J.; Zhuang, Q.; Baldocchi, D.D.; Law, B.E.; Richardson, A.D.; Chen, J.; Oren, R.; Starr, G.; Noormets, A.; Ma, S.; et al. Estimation of net ecosystem carbon exchange for the conterminous United States by combining MODIS and AmeriFlux data. Agric. For. Meteorol. 2008, 148, 1827-1847. [CrossRef]

10. Wu, C.; Niu, Z.; Gao, S. Gross primary production estimation from MODIS data with vegetation index and photosynthetically active radiation in maize. J. Geophys. Res. 2010, 115. [CrossRef]

11. Toomey, M.; Friedl, M.A.; Frolking, S.; Hufkens, K.; Klosterman, S.; Sonnentag, O.; Baldocchi, D.D.; Bernacchi, C.J.; Biraud, S.C.; Bohrer, G.; et al. Greenness indices from digital cameras predict the timing and seasonal dynamics of canopy-scale photosynthesis. Ecol. Appl. 2015, 25, 99-115. [CrossRef] [PubMed]

12. Potter, C.S.; Randerson, J.T.; Field, C.B.; Matson, P.A.; Vitousek, P.M.; Mooney, H.A.; Klooster, S.A. Terrestrial ecosystem production: A process model based on global satellite and surface data. Glob. Biogeochem. Cycle 1993, 7, 811-841. [CrossRef]

13. Prince, S.D.; Goward, S.N. Global Primary Production: A Remote Sensing Approach. J. Biogeogr. 1995, 22, 815-835. [CrossRef]

14. Xiao, X.; Hollinger, D.; Aber, J.; Goltz, M.; Davidson, E.A.; Zhang, Q.; Moore, B. Satellite-based modeling of gross primary production in an evergreen needleleaf forest. Remote Sens. Environ. 2004, 89, 519-534. [CrossRef]

15. Yuan, W.; Liu, S.; Zhou, G.; Zhou, G.; Tieszen, L.L.; Baldocchi, D.; Bernhofer, C.; Gholz, H.; Goldstein, A.H.; Goulden, M.L.; et al. Deriving a light use efficiency model from eddy covariance flux data for predicting daily gross primary production across biomes. Agric. For. Meteorol. 2007, 143, 189-207. [CrossRef]

16. Sjöström, M.; Ardö, J.; Arneth, A.; Boulain, N.; Cappelaere, B.; Eklundh, L.; de Grandcourt, A.; Kutsch, W.L.; Merbold, L.; Nouvellon, Y.; et al. Exploring the potential of MODIS EVI for modeling gross primary production across African ecosystems. Remote Sens. Environ. 2011, 115, 1081-1089. [CrossRef]

17. Lin, X.; Chen, B.; Chen, J.; Zhang, H.; Sun, S.; Xu, G.; Guo, L.; Ge, M.; Qu, J.; Li, L.; et al. Seasonal fluctuations of photosynthetic parameters for light use efficiency models and the impacts on gross primary production estimation. Agric. For. Meteorol. 2017, 236, 22-35. [CrossRef]

18. Montero, P.; Daneri, G.; González, H.E.; Iriarte, J.L.; Tapia, F.J.; Lizárraga, L.; Sanchez, N.; Pizarro, O. Seasonal variability of primary production in a fjord ecosystem of the Chilean Patagonia: Implications for the transfer of carbon within pelagic food webs. Cont. Shelf Res. 2011, 31, 202-215. [CrossRef]

19. Richardson, A.D.; Braswell, B.H.; Hollinger, D.Y.; Jenkins, J.P.; Ollinger, S.V.J.E.A. Near-surface remote sensing of spatial and temporal variation in canopy phenology. Ecol. Appl. 2009, 19, 1417-1428. [CrossRef]

20. Sonnentag, O.; Hufkens, K.; Teshera-Sterne, C.; Young, A.M.; Friedl, M.; Braswell, B.H.; Milliman, T.; O'Keefe, J.; Richardson, A.D.J.A.; Meteorology, F. Digital repeat photography for phenological research in forest ecosystems. Agric. For. Meteorol. 2012, 152, 159-177. [CrossRef]

21. Delpierre, N.; Soudani, K.; Berveiller, D.; Dufrêne, E.; Hmimina, G.; Vincent, G. "Green pointillism”: Detecting the within-population variability of budburst in temperate deciduous trees with phenological cameras. Int. J. Biometeorol. 2020, 64, 663-670. [CrossRef] [PubMed] 
22. Alberton, B.; Torres, R.d.S.; Cancian, L.F.; Borges, B.D.; Almeida, J.; Mariano, G.C.; Santos, J.D.; Morellato, L.P.C. Introducing digital cameras to monitor plant phenology in the tropics: Applications for conservation. Perspect. Ecol. Conser 2017, 15, 82-90. [CrossRef]

23. Westergaard-Nielsen, A.; Lund, M.; Hansen, B.U.; Tamstorf, M.P. Camera derived vegetation greenness index as proxy for gross primary production in a low Arctic wetland area. ISPRS J. Photogramm. Remote Sens 2013, 86, 89-99. [CrossRef]

24. Wang, H.; Jia, G.; Epstein, H.E.; Zhao, H.; Zhang, A. Integrating a PhenoCam-derived vegetation index into a light use efficiency model to estimate daily gross primary production in a semi-arid grassland. Agric. For. Meteorol. 2020, 288-289, 107983. [CrossRef]

25. Zhao, J.; Zhang, Y.; Tan, Z.; Song, Q.; Liang, N.; Yu, L.; Zhao, J. Using digital cameras for comparative phenological monitoring in an evergreen broad-leaved forest and a seasonal rain forest. Ecol. Infor. 2012, 10, 65-72. [CrossRef]

26. Saitoh, T.M.; Nagai, S.; Saigusa, N.; Kobayashi, H.; Suzuki, R.; Nasahara, K.N.; Muraoka, H. Assessing the use of camera-based indices for characterizing canopy phenology in relation to gross primary production in a deciduous broad-leaved and an evergreen coniferous forest in Japan. Ecol. Infor. 2012, 11, 45-54. [CrossRef]

27. Wang, M.; Sun, R.; Zhu, A.; Xiao, Z. Evaluation and Comparison of Light Use Efficiency and Gross Primary Productivity Using Three Different Approaches. Remote Sens. 2020, 12, 1003. [CrossRef]

28. Wolanin, A.; Camps-Valls, G.; Gómez-Chova, L.; Mateo-García, G.; van der Tol, C.; Zhang, Y.; Guanter, L. Estimating crop primary productivity with Sentinel-2 and Landsat 8 using machine learning methods trained with radiative transfer simulations. Remote Sens. Environ. 2019, 225, 441-457. [CrossRef]

29. Yang, F.; Ichii, K.; White, M.A.; Hashimoto, H.; Michaelis, A.R.; Votava, P.; Zhu, A.X.; Huete, A.; Running, S.W.; Nemani, R.R. Developing a continental-scale measure of gross primary production by combining MODIS and AmeriFlux data through Support Vector Machine approach. Remote Sens. Environ. 2007, 110, 109-122. [CrossRef]

30. Tramontana, G.; Ichii, K.; Camps-Valls, G.; Tomelleri, E.; Papale, D. Uncertainty analysis of gross primary production upscaling using Random Forests, remote sensing and eddy covariance data. Remote Sens. Environ. 2015, 168, 360-373. [CrossRef]

31. Lee, B.; Kim, E.; Lim, J.-H.; Kang, M.; Kim, J. Application of Machine Learning Algorithm and Remote-sensed Data to Estimate Forest Gross Primary Production at Multi-sites Level. Korean J. Remote Sens 2019, 35, 1117-1132. [CrossRef]

32. Du, M.; Kawashima, S.; Yonemura, S.; Zhang, X.; Chen, S. Mutual influence between human activities and climate change in the Tibetan Plateau during recent years. Glob. Planet. Chang. 2004, 41, 241-249. [CrossRef]

33. Zheng, Z.; Zhu, W.; Chen, G.; Jiang, N.; Fan, D.; Zhang, D. Continuous but diverse advancement of spring-summer phenology in response to climate warming across the Qinghai-Tibetan Plateau. Agric. For. Meteorol. 2016, 223, 194-202. [CrossRef]

34. An, S.; Chen, X.; Zhang, X.; Lang, W.; Ren, S.; Xu, L. Precipitation and Minimum Temperature are Primary Climatic Controls of Alpine Grassland Autumn Phenology on the Qinghai-Tibet Plateau. Remote Sens. 2020, 12, 431. [CrossRef]

35. Huete, A.R.; Liu, H.Q.; Batchily, K.; van Leeuwen, W. A comparison of vegetation indices over a global set of TM images for EOS-MODIS. Remote Sens. Environ. 1997, 59, 440-451. [CrossRef]

36. Shokr, M. Potential directions for applications of satellite earth observations data in Egypt. Egyptian. J. Remote Sens. Space Sci. 2011, 14,1-13. [CrossRef]

37. Liu, S.M.; Xu, Z.W.; Wang, W.Z.; Jia, Z.Z.; Zhu, M.J.; Bai, J.; Wang, J.M. A comparison of eddy-covariance and large aperture scintillometer measurements with respect to the energy balance closure problem. Hydrol. Earth Syst. Sci. 2011, 15, 1291-1306. [CrossRef]

38. Gilmanov, T.G.; Soussana, J.F.; Aires, L.; Allard, V.; Ammann, C.; Balzarolo, M.; Barcza, Z.; Bernhofer, C.; Campbell, C.L.; Cernusca, A.; et al. Partitioning European grassland net ecosystem $\mathrm{CO}_{2}$ exchange into gross primary productivity and ecosystem respiration using light response function analysis. Agric. Ecosyst. Environ. 2007, 121, 93-120. [CrossRef]

39. Wang, X.; Ma, M.; Huang, G.; Veroustraete, F.; Zhang, Z.; Song, Y.; Tan, J. Vegetation primary production estimation at maize and alpine meadow over the Heihe River Basin, China. Int. J. Appl. Earth Obs. Geoinf. 2012, 17, 94-101. [CrossRef] 
40. Ahrends, H.E.; Etzold, S.; Kutsch, W.L.; Stoeckli, R.; Bruegger, R.; Jeanneret, F.; Wanner, H.; Buchmann, N.; Eugster, W. Tree phenology and carbon dioxide fluxes: Use of digital photography for process-based interpretation at the ecosystem scale. Clim. Res. 2009, 39, 261-274. [CrossRef]

41. Knox, S.H.; Dronova, I.; Sturtevant, C.; Oikawa, P.Y.; Matthes, J.H.; Verfaillie, J.; Baldocchi, D. Using digital camera and Landsat imagery with eddy covariance data to model gross primary production in restored wetlands. Agric. For. Meteorol. 2017, 237, 233-245. [CrossRef]

42. Zhou, R.; Zhang, Y.; Song, Q.; Lin, Y.; Sha, L.; Jin, Y.; Liu, Y.; Fei, X.; Gao, J.; He, Y.; et al. Relationship between gross primary production and canopy colour indices from digital camera images in a rubber (Hevea brasiliensis) plantation, Southwest China. Forest. Ecol. Manag. 2019, 437, 222-231. [CrossRef]

43. Heinsch, F.A.; Reeves, M.; Votava, P.; Kang, S.; Milesi, C.; Zhao, M.S. User's Guide GPP and NPP (MOD17A2/A3) Products NASA MODIS Land Algorithm, Version 2.0. 2002. Available online: http: //www.ntsg.umt.edu/modis/MOD17UsersGuide.pdf (accessed on 24 December 2008).

44. Zhao, H.; Jia, G.; Wang, H.; Zhang, A.; Xu, X. Seasonal and interannual variations in carbon fluxes in East Asia semi-arid grasslands. Sci. Total Environ. 2019, 668, 1128-1138. [CrossRef] [PubMed]

45. Chai, X.; Shi, P.; Zong, N.; He, Y.; Zhang, X.; Xu, M.; Zhang, J. A growing season climatic index to simulate gross primary productivity and carbon budget in a Tibetan alpine meadow. Ecol. Indic. 2017, 81, 285-294. [CrossRef]

46. Li, F.; Wang, X.F.; Zhao, J.; Zhang, X.Q.; Zhao, Q.J. A method for estimating the gross primary production of alpine meadows using MODIS and climate data in China. Int. J. Remote Sens. 2013, 34, 8280-8300. [CrossRef]

47. Li, Z.; Yu, G.; Xiao, X.; Li, Y.; Zhao, X.; Ren, C.; Zhang, L.; Fu, Y. Modeling gross primary production of alpine ecosystems in the Tibetan Plateau using MODIS images and climate data. Remote Sens. Environ. 2007, 107, 510-519. [CrossRef]

48. Wang, X.; Ma, M.; Li, X.; Song, Y.; Tan, J.; Huang, G.; Zhang, Z.; Zhao, T.; Feng, J.; Ma, Z.; et al. Validation of MODIS-GPP product at 10 flux sites in northern China. Int. J. Remote Sens. 2013, 34, 587-599. [CrossRef]

49. Turner, D.P.; Ritts, W.D.; Zhao, M.; Kurc, S.A.; Running, S.W.J.I.T.o.G.; Sensing, R. Assessing Interannual Variation in MODIS-Based Estimates of Gross Primary Production. IEEE Trans. Geosci. Remote Sens. 2006, 44, 1899-1907. [CrossRef]

50. Xin, Q.; Broich, M.; Suyker, A.E.; Yu, L.; Gong, P. Multi-scale evaluation of light use efficiency in MODIS gross primary productivity for croplands in the Midwestern United States. Agric. For. Meteorol. 2015, 201, 111-119. [CrossRef]

51. Wei, S.; Yi, C.; Wei, F.; Hendrey, G. A global study of GPP focusing on light-use efficiency in a random forest regression model. Ecosphere 2017, 8. [CrossRef]

52. Zheng, Y.; Zhang, L.; Xiao, J.; Yuan, W.; Yan, M.; Li, T.; Zhang, Z. Sources of uncertainty in gross primary productivity simulated by light use efficiency models: Model structure, parameters, input data, and spatial resolution. Agric. For. Meteorol. 2018, 263, 242-257. [CrossRef]

53. Xu, L.; Zhang, X.; Shi, P.; Yu, G. Response of canopy quantum yield of alpine meadow to temperature under low atmospheric pressure on Tibetan Plateau. Sci. China Ser. D Earth Sci. 2006, 49, 219-225. [CrossRef]

54. Wang, H.; Jia, G.; Fu, C.; Feng, J.; Zhao, T.; Ma, Z. Deriving maximal light use efficiency from coordinated flux measurements and satellite data for regional gross primary production modeling. Remote Sens. Environ. 2010, 114, 2248-2258. [CrossRef]

Publisher's Note: MDPI stays neutral with regard to jurisdictional claims in published maps and institutional affiliations.

(C) 2020 by the authors. Licensee MDPI, Basel, Switzerland. This article is an open access article distributed under the terms and conditions of the Creative Commons Attribution (CC BY) license (http://creativecommons.org/licenses/by/4.0/). 